\title{
Endothelial heterogeneity in the umbilico-placental unit: DNA methylation as an innuendo of epigenetic diversity
}

\author{
Paola Casanello ${ }^{1,2}$, Daniela Schneider ${ }^{1}$, Emilio A. Herrera ${ }^{3}$, Ricardo Uauy ${ }^{2}$ and Bernardo J. Krause ${ }^{1}$ * \\ 'Division of Obstetrics and Gynaecology, School of Medicine, Faculty of Medicine, Pontificia Universidad Católica de Chile, Santiago, Chile \\ ${ }^{2}$ Division of Paediatrics, School of Medicine, Pontificia Universidad Católica de Chile, Santiago, Chile \\ ${ }^{3}$ Programa de Fisiopatología, Laboratorio de Función y Reactividad Vascular, Instituto de Ciencias Biomédicas, Facultad de Medicina, Universidad de Chile, \\ Santiago, Chile
}

\section{Edited by:}

Carlos Alonso Escudero, Universidad del Bio Bio, Chile

\section{Reviewed by:}

Norma Beatriz Ojeda, University of Mississippi Medical Center, USA

Carlos Alonso Escudero, Universidad del Bio Bio, Chile

${ }^{*}$ Correspondence:

Bernardo J. Krause, Division of Obstetrics and Gynaecology, School of Medicine, Faculty of Medicine, Pontificia Universidad Católica de Chile, Marcoleta 391, 8330024

Santiago, Chile

e-mail:bjkrause@uc.cl
The endothelium is a multifunctional heterogeneous tissue playing a key role in the physiology of every organ. To accomplish this role the endothelium presents a phenotypic diversity that is early prompted during vascular development, allowing it to cope with specific requirements in a time- and site-specific manner. During the last decade several reports show that endothelial diversity is also present in the umbilico-placental vasculature, with differences between macro- and microvascular vessels as well as arterial and venous endothelium. This diversity is evidenced in vitro as a higher angiogenic capacity in the microcirculation; or disparity in the levels of several molecules that control endothelial function (i.e., receptor for growth factors, vasoactive mediators, and adhesion molecules) which frequently are differentially expressed between arterial and venous endothelium. Emerging evidence suggests that endothelial diversity would be prominently driven by epigenetic mechanisms which also control the basal expression of endothelial-specific genes. This review outlines evidence for endothelial diversity since early stages of vascular development and how this heterogeneity is expressed in the umbilico-placental vasculature. Furthermore a brief picture of epigenetic mechanisms and their role on endothelial physiology emphasizing new data on umbilical and placental endothelial cells is presented. Unraveling the role of epigenetic mechanisms on long term endothelial physiology and its functional diversity would contribute to develop more accurate therapeutic interventions. Altogether these data show that micro- versus macro-vascular, or artery versus vein comparisons are an oversimplification of the complexity occurring in the endothelium at different levels, and the necessity for the future research to establish the precise source of cells which are under study.

Keywords: endothelial, epigenetics, artery, vein, placenta, umbilical

\section{INTRODUCTION}

Since the discovery of the role of endothelium on vascular tone regulation at the beginning of 1980s, a countless number of studies have shown the plethora of remarkable functions that this tissue has in vascular physiology. Notably significant advances in understanding the role of endothelium have used human umbilical and placental vessels as experimental models, which is also applied to the knowledge regarding endothelial diversity. The diversity of functions that the endothelium exerts (i.e., regulation of vessel tone, angiogenesis, immune cell adhesion and migration, exchange, and haemostasis) associates with specific "zones" of the vasculature, suggesting that endothelial cells present a phenotypic heterogeneity that supports this functional diversity (Atkins et al., 2011). From the molecular point of view endothelial cells in vivo express several proteins which allow to distinguish between arterial and venous endothelial cells and some of these patterns are preserved in vitro, suggesting that long term endothelial physiology is importantly influenced by epigenetic mechanisms (Matouk and Marsden, 2008; Aird, 2012).

\section{ORIGINS OF ENDOTHELIAL CELLS}

Vasculogenesis is the process by which vessels are formed from mesenchymal-derived hemangioblasts which differentiate into endothelial cells (Demir et al., 2007). Current evidence shows that initial stages of vascular development are determined by genetic factors (le Noble et al., 2008; Atkins et al., 2011). These processes require the expression of VEGF (Shalaby et al., 1995) and activation of downstream mitogenic effectors (Parenti et al., 1998; Shizukuda et al., 1999). However, the site from which the vascular progenitors for placental and embryo vasculogenesis emerge is still debated. It is accepted that in the embryo vascular progenitors emerge from intra- and extra-embryonic mesodermal tissues (Jin and Patterson, 2009), whilst in the placenta they arise from the extra-embryonic mesoderm (Chaddha et al., 2004). However, there is growing evidence for a crucial role of the yolk sac in embryo and placental vascular development (Freyer and Renfree, 2009). Indeed, using a sodium-calcium exchanger ( $N c x-1)$ knockout mice which fails to initiate cardiac contraction Lux et al. (2008) showed that all the hematopoietic progenitor cells emerge from the yolk sac. The origin of placental endothelial cells 
could have an important impact on its vascular physiology because arterial-venous identity is early established by environmental cues which could have diverse effects depending on the localization in the embryo.

Growth and consolidation of the placental vascular tree occurs by angiogenesis. In this process single vessels are formed by endothelial precursor cells (EPCs) which differentiate into endothelial cells, and/or proliferate from endothelial cells. These vessels can spread in two ways, (1) non-branching angiogenesis, which implies an increase in the length of the villous vessels, and (2) branching angiogenesis, in which multiple short capillary loops are formed (Demir et al., 2007), increasing the vascular surface area. After these processes have taken place, the vessels mature and their structures stabilize. Additional maturation and specialization in the vascular system are influenced by environmental signals, such as blood flow, oxygen tension, oxidative stress, and epigenetic factors (le Noble et al., 2008; Atkins etal., 2011). All these factors have been implicated in the development and function of the human placenta (Fowden et al., 2008; Burton, 2009; Dennery, 2010). Thus, angiogenesis is a complex process which involves genetic, epigenetic and environmental commands in the development and establishment of the vasculature.

\section{EPIGENETICS OVERVIEW}

During the last decade, the study of genome-environment interactions has revealed a plethora of mechanisms that modulate short and long term cellular physiology. These mechanisms involve mainly epigenetic processes which control chromatin accessibility in a gene- and cell-specific manner. Definition of epigenetics is still under debate mainly due to the several molecular mechanisms that it comprises and the heritability of these changes in an organism and its progeny; however, a simple and broad definition considers epigenetic mechanisms as "chromosome-based mechanisms that change the phenotypic plasticity in a cell or organism" (Krause etal., 2009; Gibney and Nolan, 2010).

Epigenetic mechanisms affect chromatin structure and gene expression regulating DNA and histone interactions, and the translation and stability of mRNA. Epigenetic markers such as DNA methylation, histone deacetylation, and other repressive histone post-translational modifications (PTMs) alter the structure of the chromatin, generating regions with a "closed chromatin" conformation. Conversely, DNA demethylation (potentially driven by the oxidation of methylated cytosines and their replacement by base excision repair; Kohli and Zhang, 2013), ATP-dependent chromatin remodeling, histone acetylation (Ac), and other permissive histone PTMs, convert the closed chromatin into an "open chromatin" conformation allowing binding of transcription factors and the RNA polymerase II (Figure 1). As an additional epigenetic mechanism, the presence of noncoding RNAs can post-transcriptionally repress gene expression. Detailed reviews of the diverse epigenetic mechanisms and their effects on gene expression are available (Klose and Bird, 2006;

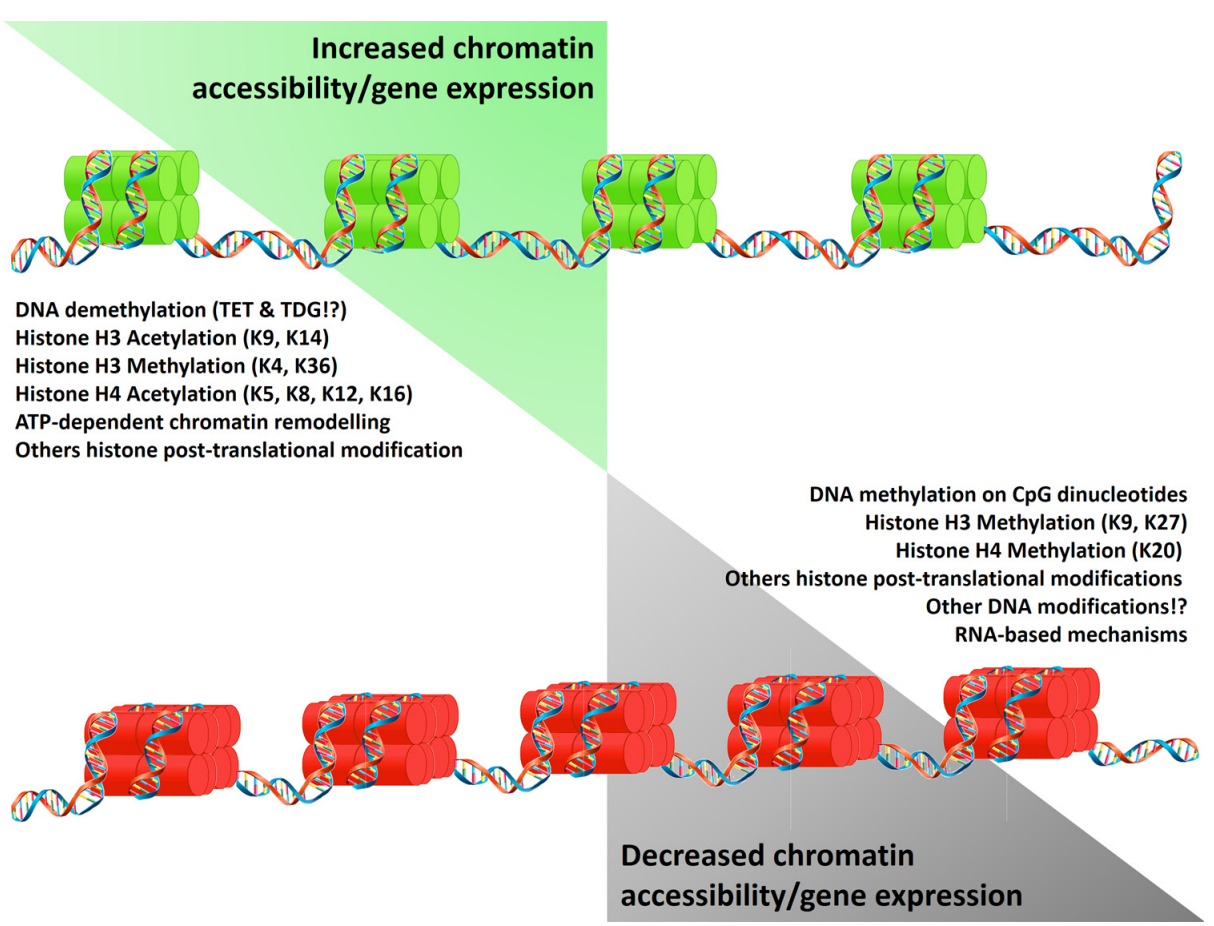

FIGURE 1 | Epigenetic mechanisms regulating gene expression. Epigenetic mechanisms control gene expression by increasing (green histones) or limiting chromatin accessibility (red histones). These states result from the equilibrium of modifications on the DNA and histones which reduce (left list) or promote (right list) DNA/histones interactions. Alternatively gene expression is limited by the presence of non-coding RNA. Symbols "!?" denote recently reported mechanisms whose effects are currently under study. 
Kouzarides, 2007; Wang et al., 2007a,b; Kaikkonen et al., 2011; Kohli and Zhang, 2013).

From a developmental perspective epigenetic mechanisms allow the generation of diverse cell phenotypes and functions of an organism from a single genome, and respond to a range of environmental fluctuations. This issue is especially evident in organs and tissues whose structure and function are under constant change across lifespan, such as the cardiovascular system (Aird, 2012). Nonetheless, placental vasculature may also be programmed by epigenetic mechanisms, which are currently under restless research.

\section{EPIGENETICS IN ENDOTHELIAL PHYSIOLOGY AND PATHOPHYSIOLOGY}

Vascular development, endothelial differentiation and function require a fine epigenetic tuning (Table 1). Initial steps of vascular development in the embryo seem to be influenced by both genetic and environmental stimuli which drive the emergence of two different populations of endothelial cells (Atkins et al., 2011). Differentiation of embryonic stem cells and EPCs into endothelial cells requires the participation of histone deacetylases (HDAC), lysine demethylases (KDM) and reduced DNA methylation in the promoter region of endothelial-specific genes (Rossig etal., 2005; Zeng etal., 2006; Lagarkova etal., 2008; Banerjee and Bacanamwo, 2010; Ohtani et al., 2011). Conversely, differentiated endothelial cells can be reprogramed to a pseudoembryonic stem cell phenotype increasing the DNA methylation status of endothelial-specific genes (Lagarkova et al., 2010). In endothelial cells, activating histone PTM, such as acetylation of $\mathrm{H} 3$ and $\mathrm{H} 4$ and methylation of $\mathrm{H} 3 \mathrm{~K} 4$, control the basal expression of vWF (Peng and Jahroudi, 2003), NOTCH4 (Wu etal., 2005), VEGF receptor 1 (Dutta et al., 2008), endomucin (Kanki etal., 2011), and eNOS (Fish etal., 2005; Gan etal., 2005).

On the other hand, HDAC activity is required for an adequate vascular integrity (Chang etal., 2006) preventing short term endothelial proliferation and angiogenesis (Ha et al., 2008; Jin etal., 2011), whilst calmodulin-lysine $N$-methyltransferase (KMT) activity has the opposite effect (Diehl et al., 2007). However, long term HDAC activity promotes angiogenesis in response to VEGF (Deroanne et al., 2002) and hypoxia (Kim et al., 2001) increasing the expression of VEGF (Ruchko et al., 2009) and eNOS (Rossig et al., 2002). Similarly, HDAC activity is increased in response to shear stress (Illi et al., 2003) improving cell survival (Zampetaki et al., 2010) and eNOS expression (Wang et al., 2010). Noteworthy, the epigenetic regulation of NOS3 gene has been extensively studied in endothelial and non-endothelial cells, showing that endothelial cells have a distinctive pattern of DNA methylation and histone PTMs (Fish and Marsden, 2006). Fish et al. (2007) reported that the decreased expression of eNOS in HUVEC exposed to acute hypoxia is controlled by the overexpression of a natural cis-antisense non-coding RNA called sONE, and changes in histone PTMs which occur specifically at the eNOS promoter (Fish et al., 2010). Additionally, abrogation of NOS3 promoter DNA methylation increases basal eNOS mRNA expression in vitro, and protects against hind-limb ischemic injury in vivo (Rao et al., 2011).

Several studies show that epigenetic mechanisms participate in the increased risk of developing vascular diseases. In humans, endothelial cells from atherosclerotic plaques have decreased levels of estrogen receptor $\beta$ along with increased DNA methylation at the promoter region of this gene, compared with those from non-atherosclerotic plaque regions (Kim et al., 2007). Deficiency of a specific KDM, lysine-specific demethylase-1 (LSD1, KDM1a), associates with decreased expression of eNOS and NO-dependent vasodilation, as well as, salt sensitive hypertension (Pojoga et al., 2011). In newborn rats with persistent pulmonary hypertension, the increased expression of eNOS mRNA is accompanied by augmented levels of acetylated $\mathrm{H} 3$ and $\mathrm{H} 4$ in the NOS3 gene promoter (Xu et al., 2010). Alternatively, cultured endothelial cells exposed to elevated levels of homocysteine, which relates with increased cardiovascular risk, present decreased proliferation and increased levels of oxidative stress. In both cases homocysteine acts inducing specific hypomethylation of the gene promoters for the cell cycle regulator cyclin A (Jamaluddin et al., 2007) and the pro-oxidant protein p66shc (Kim et al., 2011). Additionally, high glucoseinduced endothelial dysfunction requires the participation of HAT (Chen etal., 2010) and KMT (El-Osta et al., 2008), generating important epigenomic changes (Pirola et al., 2011), which can persist several days after the exposure to the noxa (El-Osta et al., 2008).

Notably, vascular physiology is also influenced by epigenetic mechanisms occurring in smooth muscle cells (SMCs). Development of vascular dysfunction is accompanied by changes in SMC phenotype, which shift from a "contractile" to a "synthetic" and

Table 1 | Effect of DNA methylation and histone post-translational modifications (PTMs) on endothelial cell physiology.

\begin{tabular}{|c|c|c|}
\hline Mechanism & Process & Reference \\
\hline DNA methylation & $\begin{array}{l}\text { In vitro and in vivo progenitor endothelial cells differentiation } \\
\text { Activation of tissue-specific genes } \\
\text { Ischemia-induced neo-vascularization }\end{array}$ & $\begin{array}{l}\text { Chan etal. (2004), Lagarkova etal. (2008), Ohtani etal. } \\
\text { (2011), Rao etal. (2011) }\end{array}$ \\
\hline Histone acetylation & $\begin{array}{l}\text { Hypoxia-, VEGF- and shear stress- induced angiogenesis } \\
\text { VEGF-induced progenitor endothelial cells differentiation } \\
\text { Basal endothelial cell-specific genes }\end{array}$ & $\begin{array}{l}\text { Kim etal. (2001), Deroanne et al. (2002), Rossig etal. } \\
\text { (2002), Peng and Jahroudi (2003), Illi etal. (2005), } \\
\text { Zeng et al. (2006), Wu etal. (2005) }\end{array}$ \\
\hline Other histone PTMs & Progenitor endothelial cells differentiation & Ohtani etal. (2011), Fish et al. (2010) \\
\hline
\end{tabular}

Hypoxia induced eNOS down-regulation 
"pro-inflammatory" phenotype with long term consequences in the contractile properties of vessels (Owens et al., 2004; Orr et al., 2010). Increasing data shows that this "phenotypic switching" requires the participation of epigenetic mechanisms which establish an altered SMC function (Alexander and Owens, 2012).

\section{PHENOTYPIC AND EPIGENETIC DIVERSITY IN THE UMBILICO-PLACENTAL ENDOTHELIUM}

Pioneer studies by Lang et al. (1993) demonstrated that micro- and macrovascular umbilico-placental endothelium present different immunoreactivity to diverse molecular markers for endothelial cells, suggesting the presence of a phenotypic endothelial diversity in the placenta. Additional evidence from cultured human endothelial cells isolated from the placental microcirculation (PLEC) and the umbilical vein (HUVEC) show that microvascular endothelial cells express higher levels of vascular mediators (angiotensin II, endothelin, and thromboxane; Lang, 2003). Also a differential pattern of homeobox genes (Murthi et al., 2007, 2008) and higher cholesterol transport capacity (Stefulj et al., 2009) in PLEC compared to HUVEC has been shown.

Notably, studies on endothelial cells from arteries and veins have revealed important differences between arterial and venous cells at the same vascular level. In fact the higher mitogenic response observed in PLEC (Lang, 2003) may reflect the combination of a high response to VEGF present in arterial PLEC (PLAEC) and to PIGF in venous endothelial cells (PLVEC; Lang et al., 2008). A transcriptomic analysis between PLAEC and PLVEC showed that they have differential expression of more than 3,000 genes (Lang et al., 2008). Similarly there is a differential expression of eNOS, a key vascular gene, between micro- and macrovascular, and venous and arterial endothelium (Andersen et al., 2009; Krause et al., 2012) being more homogenous at the arterial side (Andersen etal., 2009). This opens the queries about the differences initially reported between micro- and macrovascular endothelium reflecting an endothelial diversity between large and small vessels, and whether they include variances between arteries and veins.

Several studies comparing simultaneously umbilical arterial (HUAEC) and venous (HUVEC) endothelium support the concept that these cells are not a homogenous population, and the necessity of clarifying the precise source of cells when the term "macrovasculature" is used. A general characterization shows that there is a different profile of phospholipids with higher levels of arachidonic acid-related species and heterogeneous expression pattern of selenoproteins (Miller et al., 2002) in HUAEC compared to HUVEC (Takamura et al., 1990). Alongside the classical molecular markers for arterial endothelium, cultured HUAEC express higher levels of PAI 1 (Gallicchio et al., 1994), Cx40 (Van Rijen et al., 1997), 17ß-HSD2 (Simard et al., 2011), and VCAM-1 (Egorova et al., 2012); and lower levels of von Willebrand Factor (Shahani et al., 2010) and estrogen receptors beta (ER $\beta$; Simard et al., 2011) compared with HUVEC. On the other hand expressions of pro-constrictive mediators such as angiotensin converting enzyme (Ito et al., 2002) and ET-1 (Egorova et al., 2012) are different in HUVEC relative to HUAEC. Furthermore, expression and activity of eNOS are higher in freshly isolated HUVEC than HUAEC (Andersen etal., 2009) and this expression pattern is also observed in cells cultured up to third passage (Krause et al., 2012). Whether these differences reflects the physiology of umbilical (and potentially placental) arteries and veins, and how they are preserved in vitro need further examination. Two recent reports show that the differential gene expression between HUAEC and HUVEC is partially controlled by specific transcription factors. Overexpression of the venous-specific nuclear receptor COUPTFII in HUAEC decreases the expression of arterial markers (i.e., Hey2, EphrinB2 and NICD4), and its down-regulation in HUVEC increases the expression of arterial markers such as VEGF-A, Dll and EphrinB2 (Korten et al., 2013). Moreover, in vitro simultaneous overexpression of eight arterial-specific transcription factors turns the HUVEC transcriptome into a HUAEC-like pattern (Aranguren et al., 2013).

Therefore, the phenotypic diversity in the umbilico-placental circulation is apparently commanded, at least in part, by an equivalent diversity in epigenetic mechanisms.

\section{ENDOTHELIAL DIVERSITY AND ANGIOGENESIS}

In terms of angiogenesis, microvascular endothelial cells present a higher mitogenic response to VEGF, PIGF (Lang, 2003; Lang et al., 2008), and prokineticin 1 (Brouillet et al., 2010) compared with HUVEC, along with an increased expression of pro-angiogenic HOX genes (i.e., TLX1, TLX2, and PHOX1; Murthi et al., 2008). These data are in agreement with the notion that placental angiogenic capacity is augmented in microvascular vessels compared to endothelial cells from larger vessels. However, it is also possible to find significant differences in the angiogenic response in endothelial cells from umbilical arteries and veins. In vivo VEGFR3, which is commonly expressed in lymphatic endothelium or during active angiogenesis (Koch and Claesson-Welsh, 2012), is absent in HUAEC but expressed in HUVEC (Veikkola et al., 2003). Moreover in vitro chemotaxis induced by VEGFA or FGF2 is higher in HUVEC compared to HUAEC (Barkefors et al., 2008), and netrin-1 prevents the VEGF-induced migration in HUAEC without effect on HUVEC (Lu et al., 2004). Further studies are needed to address the effects and the role on placental physiology of this increased angiogenic response observed in HUVEC.

\section{ENDOTHELIAL DIVERSITY IN RESPONSE TO STRESS}

Placental vascular and endothelial physiology, similar to adult vasculature, are importantly influenced by stimuli such as altered shear stress and oxygen levels whose effects are apparently different between arteries and veins. Normally arterial endothelium is exposed to higher shear stress and therefore it is plausible to predict a stronger response to increasing stress. In fact pulsatile shear stress increases the expression of arterial markers (i.e., Heyl, Hey1, and ephrinB2) in HUAEC but decreases the expression of venous markers (COUP-TFII) in HUVEC (Buschmann et al., 2010). Laminar shear stress have similar effects on the expression of arterial-venous markers in these cells, and increases the levels of S-nitrosylated proteins (Hoffmann et al., 2003) endothelin-1, VCAM, and vWF (Egorova et al., 2012) in HUAEC compared to HUVEC. Whether these differences are observed in microvascular endothelial cells remains to be determined.

Some evidence regarding the effects of low oxygen levels on endothelial function in placental large and small vessels, as well 
as arteries and veins, show a differential vascular response to hypoxia throughout the placenta (Krause et al., 2011, 2012). On the other hand placental endothelium is importantly exposed to low oxygen levels and oxidative stress which are negative regulator of placental angiogenesis (Burton et al., 2009). A reduction in oxygen levels from 21 to $12 \% \mathrm{O}_{2}$ decreases placental venous microvascular endothelial cells viability with no effect on their arterial counterparts (Lassance et al., 2012), and PLAEC exposed to $3 \% \mathrm{O}_{2}$ show an increased mitogenic response to VEGFA and FGF2 compared to cells cultured at $21 \% \mathrm{O}_{2}$ (Wang et al., 2009). This higher response to VEGFA and FGF2 is also observed in HUAEC exposed to physiological levels of oxygen $\left(3-5 \% \mathrm{O}_{2}\right.$; Jiang et al., 2013). Additionally, hypoxia $\left(1 \% \mathrm{O}_{2}\right)$ increases the expression of the pro-angiogenic factor protease-activated receptor 2 in HUVEC and this effect is higher in HUAEC (Svensson et al., 2011).

Altogether these data show that venous-arterial endothelial phenotypic diversity occurs among umbilical and placental vessels (Figure 2). Further studies should include control comparison between arterial and venous endothelial cells from the same branching level to rule out potential differences attributable to arteries and veins rather than micro- and macrovascular vessels. It is worth to note that most of the differences occurring among these cells types could be reverted by genetic manipulation. However, its persistence in vitro suggests that additional mechanisms controlling gene expression should be operating, arguing for a crucial role for epigenetics in this process.

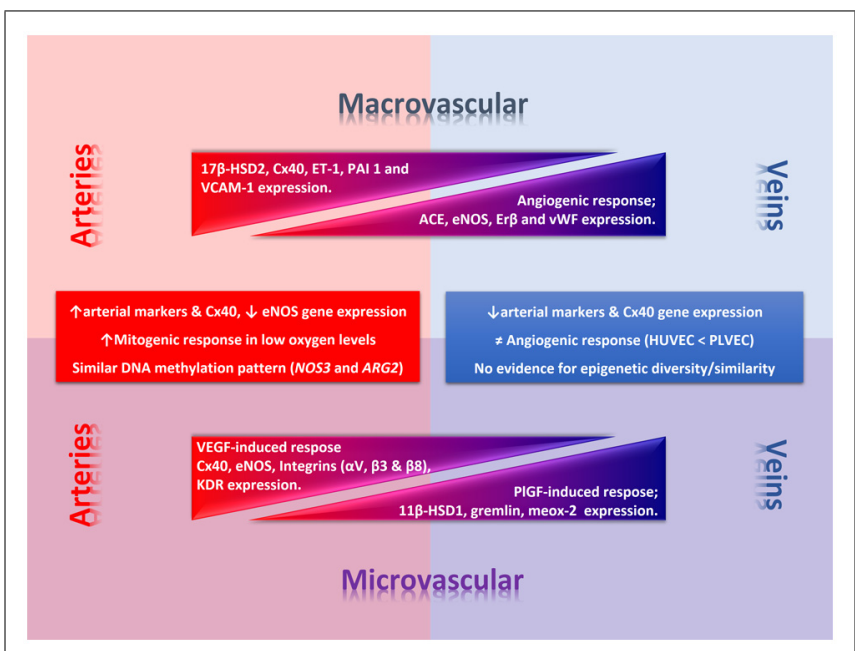

FIGURE 2 | Phenotypic diversity in the umbilico-placental

endothelium. Umbilical (macrovascular) and placental (microvascular) endothelial cells present a phenotypic diversity characterized by a differential response to angiogenic factors and gene expression of key endothelial genes. In the figure thickness of the triangle denotes deferential relative expression (or response) regarding arteries or veins at each level. Square text box includes common traits between macro- and micro-vascular arterial or venous endothelial cells. $11 \beta-H S D 1$,

$11 \beta$-hydroxysteroid dehydrogenase $1 ; 17 \beta$-HSD2, $17 \beta$ hydroxysteroid dehydrogenase 2; ARG2, arginase-2 gene; Cx40, conexin-40; eNOS, endothelial nitric oxide synthase; ET-1, endothelin-1; KDR, vascular endothelial growth factor (VEGF) receptor 2; NOS3, eNOS gene; PAI 1, plasminogen activator inhibitor-1; PIGF, placental growth factor; VCAM-1, vascular cell adhesion molecule 1.

\section{EPIGENETIC AND PLACENTAL ENDOTHELIAL DIVERSITY}

Compelling evidence shows the fundamental role of epigenetics controlling the endothelial-specific gene expression, however, the next frontier is to determine how epigenetic mechanisms influence the endothelial functional diversity. Two recent reports studying placental and umbilical endothelial cells suggest the presence of significant differences in the DNA methylation of gene promoters which could be responsible for the differential gene expression present in these cells.

A comparison of the genome-wide DNA methylation profile in PLAEC and PLVEC show that venous endothelial cells present lower levels of global methylation compared to PLAEC (Joo et al., 2013) which could reflect the immature phenotype of PLVEC (Lang etal., 2008). Further analysis show the presence of several genes which are differentially methylated between PLAEC and PLVEC, and some of them present an inverse correlation between the level of methylation and the gene expression. Notably those genes are considered endothelial markers and play a key role in vascular physiology, such as eNOS, vWF, Conexin40, VEGFR1, VEGFC, and angiopiotein-1. However, there are endothelial genes whose promoters do not present any correlation between methylation levels and gene expression, such as VEGFR2, Hey2, NOTCH, EphB2, and EphB4 (Joo et al., 2013).

Conversely, the comparison of DNA methylation status of NOS3 (eNOS) and ARG2 (arginase-2) promoters by pyrosequencing in HUAEC, PLAEC and HUVEC, suggest the presence of site-specific differences between these cells. Methylation status at NOS3 promoter in umbilical and placental endothelial cells showed differences in three specific CpG between arterial and venous endothelial cells (Krause et al., 2013). Two of these differentially methylated CpGs correspond to the reported hypoxia response element ( -5369 and -5375 ; Coulet et al., 2003) which regulates the response to hypoxia and show lower methylation levels in PLAEC and HUAEC compared to HUVEC. Whether this variation participates in the differential regulation of eNOS expression in response to hypoxia that has been reported between HUAEC and HUVEC (Krause et al., 2012) needs to be addressed. An additional differentially methylated CpG is located at -352 from the transcription starting site, showing a higher methylation pattern in arterial relative to venous cells. Moreover the methylation status at this $\mathrm{CpG}$ suggests an inverse correlation between DNA methylation and eNOS expression, which is higher in HUVEC (lower methylation levels) compared to HUAEC (Krause et al., 2012,2013). It is also reported that CpG -352 is differentially methylated between HUVEC and human dermal microvascular endothelial cells (Chan etal., 2004), having the later a methylation status comparable to that found in HUAEC and PLAEC, which suggest that $\mathrm{CpG}-352$ might play a role in the differential regulation of basal eNOS expression in arterial and venous endothelial cells. Krause et al. (2013) compared the NOS3 promoter DNA methylation status between control and endothelial cells isolated from pregnancies with intrauterine growth restriction (IUGR). Remarkably changes in DNA methylation in IUGR cells are restricted to those CpGs that are differentially methylated in normal endothelial cells. In fact, IUGR HUAEC and PLAEC present similar changes at CpGs - 5375 (increased methylation) and -352 (decreased methylation) compared with normal cells, 
and these methylation levels are comparable to that find in normal HUVEC. Conversely, changes in the DNA methylation status of IUGR HUVEC where at CpGs - 5369 (decreased methylation) and -352 (increased methylation), and they are comparable to those find in normal HUAEC and PLAEC. The methylation levels at CPG -352 in IUGR HUAEC and HUVEC are also related with the levels of mRNA for eNOS (Krause et al., 2013), reinforcing the potential importance of $\mathrm{CpG}-352$ in the regulation of basal eNOS expression. Finally analysis of methylation status of ARG2 promoter in HUAEC, PLAEC, and HUVEC show a single difference between PLAEC and HUVEC, however, it is still unknown if there is a correlation with arginase- 2 expression and activity.

DNA methylation is one of the main epigenetic mechanisms that controls long term gene expression, showing a high reproducibility after every cellular replication and this characteristic is driven by the activity of DNA methyltransferase-1 (DNMT1). In IUGR HUAEC and HUVEC DNMT1 silencing shows a differential effect, reducing and increasing basal eNOS expression, respectively (Krause et al., 2013). Silencing of DNMT1 restores to normal eNOS mRNA levels in IUGR HUAEC and HUVEC, and this effect is not observed on arginase-2 expression where it further increases its expression in IUGR HUVEC, without any effect in IUGR HUAEC (Krause et al., 2013). This suggests that DNA methylation (Jamaluddin etal., 2007; Banerjee and Bacanamwo, 2010; Kim et al., 2011) and other epigenetic mechanisms (Kim et al., 2001; Deroanne et al., 2002; Fish et al., 2010) control gene expression in endothelial cells in a gene-specific manner.

Although the studies in PLAEC and PLVEC (Joo et al., 2013), and in HUAEC and HUVEC (Krause et al., 2013) used two different approaches to analyze the DNA methylation patterns, there are some similarities in the outcomes. First, both studies show that methylation status of NOS3 proximal promoter inversely correlates with the levels of mRNA for eNOS, and this occurs in cells exposed for several days to culture conditions. Second, PLAEC and PLVEC show differential levels arginase- 2 expression without differences in the DNA methylation in ARG2 promoter, whilst in control and IUGR HUAEC differences in DNA methylation are not associated to difference in arginase-2 expression. Finally, DNMT1 silencing in IUGR cells normalize eNOS expression but not arginase-2 expression.

\section{CONCLUSION}

Altogether these seminal data show that epigenetic mechanisms could be responsible for the phenotypic diversity of endothelial cells in the umbilico-placental unit, and these mechanisms would be operating in a cell- and gene-specific manner. The current research on the area is offering novel data about potential mechanisms but still further studies are required to have a comprehensive picture of the additional epigenetic mechanisms controlling the gene expression in physiological and pathophysiological conditions and its consequences in umbilico-placental functions.

\section{ACKNOWLEDGMENT}

This work was funded by FONDECYT 1110595, 1120928, 1130801 .

\section{REFERENCES}

Aird, W. C. (2012). Endothelial cell heterogeneity. Cold Spring Harb. Perspect. Med. 2:a006429. doi: 10.1101/cshperspect.a006429

Alexander, M. R., and Owens, G. K. (2012). Epigenetic control of smooth muscle cell differentiation and phenotypic switching in vascular development and disease. Annu. Rev. Physiol. 74, 13-40. doi: 10.1146/annurev-physiol-012110-142315

Andersen, M. R., Simonsen, U., Uldbjerg, N., Aalkjaer, C., and Stender, S. (2009). Smoking cessation early in pregnancy and birth weight, length, head circumference, and endothelial nitric oxide synthase activity in umbilical and chorionic vessels: an observational study of healthy singleton pregnancies. Circulation 119 , 857-864. doi: 10.1161/CIRCULATIONAHA.107.755769

Aranguren, X. L., Agirre, X., Beerens, M., Coppiello, G., Uriz, M., Vandersmissen, I., et al. (2013). Unraveling a novel transcription factor code determining the human arterial-specific endothelial cell signature. Blood 122, 3982-3992. doi: 10.1182/blood-2013-02-483255

Atkins, G. B., Jain, M. K., and Hamik, A. (2011). Endothelial differentiation: molecular mechanisms of specification and heterogeneity. Arterioscler. Thromb. Vasc. Biol. 31, 1476-1484. doi: 10.1161/ATVBAHA.111.228999

Banerjee, S., and Bacanamwo, M. (2010). DNA methyltransferase inhibition induces mouse embryonic stem cell differentiation into endothelial cells. Exp. Cell Res. 316, 172-180. doi: 10.1016/j.yexcr.2009.08.011

Barkefors, I., Le Jan, S., Jakobsson, L., Hejll, E., Carlson, G., Johansson, H., et al. (2008). Endothelial cell migration in stable gradients of vascular endothelial growth factor A and fibroblast growth factor 2: effects on chemotaxis and chemokinesis. J. Biol. Chem. 283, 13905-13912. doi: 10.1074/jbc.M704917200

Brouillet, S., Hoffmann, P., Benharouga, M., Salomon, A., Schaal, J. P., Feige, J. J., et al. (2010). Molecular characterization of EG-VEGF-mediated angiogenesis: differential effects on microvascular and macrovascular endothelial cells. Mol. Biol. Cell 21, 2832-2843. doi: 10.1091/mbc.E10-01-0059

Burton, G. J. (2009). Oxygen, the Janus gas; its effects on human placental development and function. J. Anat. 215, 27-35. doi: 10.1111/j.1469-7580.2008.00978.x

Burton, G. J., Charnock-Jones, D. S., and Jauniaux, E. (2009). Regulation of vascular growth and function in the human placenta. Reproduction 138, 895-902. doi: 10.1530/REP-09-0092

Buschmann, I., Pries, A., Styp-Rekowska, B., Hillmeister, P., Loufrani, L., Henrion, D., et al. (2010). Pulsatile shear and Gja5 modulate arterial identity and remodeling events during flow-driven arteriogenesis. Development 137, 2187-2196. doi: 10.1242/dev.045351

Chaddha, V., Viero, S., Huppertz, B., and Kingdom, J. (2004). Developmental biology of the placenta and the origins of placental insufficiency. Semin. Fetal Neonatal Med. 9, 357-369. doi: 10.1016/j.siny.2004.03.006

Chan, Y., Fish, J. E., D'abreo, C., Lin, S., Robb, G. B., Teichert, A. M., et al. (2004). The cell-specific expression of endothelial nitric-oxide synthase: a role for DNA methylation. J. Biol. Chem. 279, 35087-35100. doi: 10.1074/jbc.M4050 63200

Chang, S., Young, B. D., Li, S., Qi, X., Richardson, J. A., and Olson, E. N. (2006). Histone deacetylase 7 maintains vascular integrity by repressing matrix metalloproteinase 10. Cell 126, 321-334. doi: 10.1016/j.cell.2006.05.040

Chen, S., Feng, B., George, B., Chakrabarti, R., Chen, M., and Chakrabarti, S. (2010). Transcriptional coactivator $\mathrm{p} 300$ regulates glucose-induced gene expression in endothelial cells. Am. J. Physiol. Endocrinol. Metab. 298, E127-E137. doi: 10.1152/ajpendo.00432.2009

Coulet, F., Nadaud, S., Agrapart, M., and Soubrier, F. (2003). Identification of hypoxia-response element in the human endothelial nitric-oxide synthase gene promoter. J. Biol. Chem. 278, 46230-46240. doi: 10.1074/jbc. M305420200

Demir, R., Seval, Y., and Huppertz, B. (2007). Vasculogenesis and angiogenesis in the early human placenta. Acta Histochem. 109, 257-265. doi: 10.1016/j.acthis.2007.02.008

Dennery, P. A. (2010). Oxidative stress in development: nature or nurture? Free Radic. Biol. Med. 49, 1147-1151. doi: 10.1016/j.freeradbiomed.2010.07.011

Deroanne, C. F., Bonjean, K., Servotte, S., Devy, L., Colige, A., Clausse, N., et al. (2002). Histone deacetylases inhibitors as anti-angiogenic agents altering vascular endothelial growth factor signaling. Oncogene 21, 427-436. doi: 10.1038/sj.onc. 1205108

Diehl, F., Rossig, L., Zeiher, A. M., Dimmeler, S., and Urbich, C. (2007). The histone methyltransferase MLL is an upstream regulator of endothelial-cell sprout formation. Blood 109, 1472-1478. doi: 10.1182/blood-2006-08-039651 
Dutta, D., Ray, S., Vivian, J. L., and Paul, S. (2008). Activation of the VEGFR1 chromatin domain: an angiogenic signal-ETS1/HIF-2alpha regulatory axis. $J$. Biol. Chem. 283, 25404-25413. doi: 10.1074/jbc.M804349200

Egorova, A. D., Deruiter, M. C., De Boer, H. C., Van De Pas, S., Gittenberger-De Groot, A. C., Van Zonneveld, A. J., et al. (2012). Endothelial colony-forming cells show a mature transcriptional response to shear stress. In Vitro Cell. Dev. Biol. Anim. 48, 21-29. doi: 10.1007/s11626-011-9470-Z

El-Osta, A., Brasacchio, D., Yao, D., Pocai, A., Jones, P. L., Roeder, R. G., et al (2008). Transient high glucose causes persistent epigenetic changes and altered gene expression during subsequent normoglycemia. J. Exp. Med. 205, 2409-2417. doi: $10.1084 /$ jem.20081188

Fish, J. E., and Marsden, P. A. (2006). Endothelial nitric oxide synthase: insight into cell-specific gene regulation in the vascular endothelium. Cell. Mol. Life Sci. 63, 144-162. doi: 10.1007/s00018-005-5421-8

Fish, J. E., Matouk, C. C., Rachlis, A., Lin, S., Tai, S. C., D’abreo, C., et al. (2005). The expression of endothelial nitric-oxide synthase is controlled by a cell-specific histone code. J. Biol. Chem. 280, 24824-24838. doi: 10.1074/jbc.M502115200

Fish, J. E., Matouk, C. C., Yeboah, E., Bevan, S. C., Khan, M., Patil, K., et al. (2007). Hypoxia-inducible expression of a natural cis-antisense transcript inhibits endothelial nitric-oxide synthase. J. Biol. Chem. 282, 15652-15666. doi 10.1074/jbc.M608318200

Fish, J. E., Yan, M. S., Matouk, C. C., St Bernard, R., Ho, J. J., Gavryushova, A., et al. (2010). Hypoxic repression of endothelial nitric-oxide synthase transcription is coupled with eviction of promoter histones. J. Biol. Chem. 285, 810-826. doi: 10.1074/jbc.M109.067868

Fowden, A. L., Forhead, A. J., Coan, P. M., and Burton, G. J. (2008). The placenta and intrauterine programming. J. Neuroendocrinol. 20, 439-450. doi: 10.1111/j.13652826.2008.01663.x

Freyer, C., and Renfree, M. B. (2009). The mammalian yolk sac placenta. J. Exp. Zool. B Mol. Dev. Evol. 312, 545-554. doi: 10.1002/jez.b.21239

Gallicchio, M., Argyriou, S., Ianches, G., Filonzi, E. L., Zoellner, H., Hamilton, J. A., et al. (1994). Stimulation of PAI-1 expression in endothelial cells by cultured vascular smooth muscle cells. Arterioscler. Thromb. 14, 815-823. doi: 10.1161/01.ATV.14.5.815

Gan, Y., Shen, Y. H., Wang, J., Wang, X., Utama, B., and Wang, X. L. (2005). Role of histone deacetylation in cell-specific expression of endothelial nitric-oxide synthase. J. Biol. Chem. 280, 16467-16475. doi: 10.1074/jbc.M412960200

Gibney, E. R., and Nolan, C. M. (2010). Epigenetics and gene expression. Heredity (Edinb.) 105, 4-13. doi: 10.1038/hdy.2010.54

Ha, C. H., Jhun, B. S., Kao, H. Y., and Jin, Z. G. (2008). VEGF stimulates HDAC7 phosphorylation and cytoplasmic accumulation modulating matrix metalloproteinase expression and angiogenesis. Arterioscler. Thromb. Vasc. Biol. 28, 1782-1788. doi: 10.1161/ATVBAHA.108.172528

Hoffmann, J., Dimmeler, S., and Haendeler, J. (2003). Shear stress increases the amount of S-nitrosylated molecules in endothelial cells: important role for signal transduction. FEBS Lett. 551, 153-158. doi: 10.1016/S0014-5793(03)00917-7

Illi, B., Nanni, S., Scopece, A., Farsetti, A., Biglioli, P., Capogrossi, M. C., et al. (2003). Shear stress-mediated chromatin remodeling provides molecular basis for flow-dependent regulation of gene expression. Circ. Res. 93, 155-161. doi: 10.1161/01.RES.0000080933.82105.29

Illi, B., Scopece, A., Nanni, S., Farsetti, A., Morgante, L., Biglioli, P., et al. (2005). Epigenetic histone modification and cardiovascular lineage programming in mouse embryonic stem cells exposed to laminar shear stress. Circ. Res. 96, 501-508. doi: 10.1161/01.RES.0000159181.06379.63.

Ito, M., Itakura, A., Ohno, Y., Nomura, M., Senga, T., Nagasaka, T., et al. (2002). Possible activation of the renin-angiotensin system in the fetoplacental unit in preeclampsia. J. Clin. Endocrinol. Metab. 87, 1871-1878. doi: 10.1210/jcem.87.4.8422

Jamaluddin, M. D., Chen, I., Yang, F., Jiang, X., Jan, M., Liu, X., et al. (2007). Homocysteine inhibits endothelial cell growth via DNA hypomethylation of the cyclin A gene. Blood 110, 3648-3655. doi: 10.1182/blood-2007-06-096701

Jiang, Y. Z., Wang, K., Li, Y., Dai, C. F., Wang, P., Kendziorski, C., et al. (2013). Enhanced cellular responses and distinct gene profiles in human fetoplacental artery endothelial cells under chronic low oxygen. Biol. Reprod. 89, 133. doi: 10.1095/biolreprod.113.110551

Jin, G., Bausch, D., Knightly, T., Liu, Z., Li, Y., Liu, B., et al. (2011). Histone deacetylase inhibitors enhance endothelial cell sprouting angiogenesis in vitro. Surgery 150, 429-435. doi: 10.1016/j.surg.2011.07.001
Jin, S. W., and Patterson, C. (2009). The opening act: vasculogenesis and the origins of circulation. Arterioscler. Thromb. Vasc. Biol. 29, 623-629. doi: 10.1161/ATVBAHA.107.161539

Joo, J. E., Hiden, U., Lassance, L., Gordon, L., Martino, D. J., Desoye, G., et al. (2013). Variable promoter methylation contributes to differential expression of key genes in human placenta-derived venous and arterial endothelial cells. BMC Genomics 14:475. doi: 10.1186/1471-2164-14-475

Kaikkonen, M. U., Lam, M. T., and Glass, C. K. (2011). Non-coding RNAs as regulators of gene expression and epigenetics. Cardiovasc. Res. 90, 430-440. doi: $10.1093 / \mathrm{cvr} / \mathrm{cvr} 097$

Kanki, Y., Kohro, T., Jiang, S., Tsutsumi, S., Mimura, I., Suehiro, J., et al. (2011). Epigenetically coordinated GATA2 binding is necessary for endotheliumspecific endomucin expression. EMBO J. 30, 2582-2595. doi: 10.1038/emboj. 2011.173

Kim, C. S., Kim, Y. R., Naqvi, A., Kumar, S., Hoffman, T. A., Jung, S. B., et al. (2011). Homocysteine promotes human endothelial cell dysfunction via sitespecific epigenetic regulation of p66shc. Cardiovasc. Res. 92, 466-475. doi: $10.1093 / \mathrm{cvr} / \mathrm{cvr} 250$

Kim, J., Kim, J. Y., Song, K. S., Lee, Y. H., Seo, J. S., Jelinek, J., et al. (2007). Epigenetic changes in estrogen receptor beta gene in atherosclerotic cardiovascular tissues and in-vitro vascular senescence. Biochim. Biophys. Acta 1772, 72-80. doi: 10.1016/j.bbadis.2006.10.004

Kim, M. S., Kwon, H. J., Lee, Y. M., Baek, J. H., Jang, J. E., Lee, S. W., et al. (2001). Histone deacetylases induce angiogenesis by negative regulation of tumor suppressor genes. Nat. Med. 7, 437-443. doi: 10.1038/86507

Klose, R. J., and Bird, A. P. (2006). Genomic DNA methylation: the mark and its mediators. Trends Biochem. Sci. 31, 89-97. doi: 10.1016/j.tibs.2005.12.008

Koch, S., and Claesson-Welsh, L. (2012). Signal transduction by vascular endothelial growth factor receptors. Cold Spring Harb. Perspect. Med. 2:a006502. doi: $10.1101 /$ cshperspect.a006502

Kohli, R. M., and Zhang, Y. (2013). TET enzymes, TDG and the dynamics of DNA demethylation. Nature 502, 472-479. doi: 10.1038/nature12750

Korten, S., Brunssen, C., Poitz, D. M., Grossklaus, S., Brux, M., Schnittler, H. J., et al. (2013). Impact of Hey2 and COUP-TFII on genes involved in arteriovenous differentiation in primary human arterial and venous endothelial cells. Basic Res. Cardiol. 108, 362. doi: 10.1007/s00395-013-0362-0.

Kouzarides, T. (2007). Chromatin modifications and their function. Cell 128, 693705. doi: 10.1016/j.cell.2007.02.005

Krause, B., Sobrevia, L., and Casanello, P. (2009). Epigenetics: new concepts of old phenomena in vascular physiology. Curr. Vasc. Pharmacol. 7, 513-520. doi: $10.2174 / 157016109789043883$

Krause, B. J., Costello, P. M., Munoz-Urrutia, E., Lillycrop, K. A., Hanson, M. A., and Casanello, P. (2013). Role of DNA methyltransferase 1 on the altered eNOS expression in human umbilical endothelium from intrauterine growth restricted fetuses. Epigenetics 8, 944-952. doi: 10.4161/epi.25579

Krause, B. J., Hanson, M. A., and Casanello, P. (2011). Role of nitric oxide in placental vascular development and function. Placenta 32:797-805. doi: 10.1016/j.placenta.2011.06.025

Krause, B. J., Prieto, C. P., Munoz-Urrutia, E., Martin, S. S., Sobrevia, L., and Casanello, P. (2012). Role of arginase-2 and eNOS in the differential vascular reactivity and hypoxia-induced endothelial response in umbilical arteries and veins. Placenta 33:360-366. doi: 10.1016/j.placenta.2012.02.006

Lagarkova, M. A., Shutova, M. V., Bogomazova, A. N., Vassina, E. M., Glazov, E. A., Zhang, P., et al. (2010). Induction of pluripotency in human endothelial cells resets epigenetic profile on genome scale. Cell Cycle 9, 937-946. doi: 10.4161/cc.9.5.10869

Lagarkova, M. A., Volchkov, P. Y., Philonenko, E. S., and Kiselev, S. L. (2008). Efficient differentiation of hESCs into endothelial cells in vitro is secured by epigenetic changes. Cell Cycle 7, 2929-2935. doi: 10.4161/cc.7.18.6700

Lang, I. (2003). Heterogeneity of microvascular endothelial cells isolated from human term placenta and macrovascular umbilical vein endothelial cells. Eur. J. Cell Biol. 82, 163-173. doi: 10.1078/0171-9335-00306

Lang, I., Hartmann, M., Blaschitz, A., Dohr, G., Skofitsch, G., and Desoye, G. (1993). Immunohistochemical evidence for the heterogeneity of maternal and fetal vascular endothelial cells in human full-term placenta. Cell Tissue Res. 274, 211-218. doi: 10.1007/BF00318740

Lang, I., Schweizer, A., Hiden, U., Ghaffari-Tabrizi, N., Hagendorfer, G., Bilban, M., et al. (2008). Human fetal placental endothelial cells have a mature arterial 
and a juvenile venous phenotype with adipogenic and osteogenic differentiation potential. Differentiation 76, 1031-1043. doi: 10.1111/j.1432-0436.2008 00302.x

Lassance, L., Miedl, H., Konya, V., Heinemann, A., Ebner, B., Hackl, H., etal. (2012). Differential response of arterial and venous endothelial cells to extracellular matrix is modulated by oxygen. Histochem. Cell Biol. doi: 10.1007/s00418-012-0917-4 [Epub ahead of print].

le Noble, F., Klein, C., Tintu, A., Pries, A., and Buschmann, I. (2008). Neural guidance molecules, tip cells, and mechanical factors in vascular development. Cardiovasc. Res. 78, 232-241. doi: 10.1093/cvr/cvn058

Lu, X., Le Noble, F., Yuan, L., Jiang, Q., De Lafarge, B., Sugiyama, D., et al. (2004). The netrin receptor UNC5B mediates guidance events controlling morphogenesis of the vascular system. Nature 432, 179-186. doi: 10.1038/nature03080

Lux, C. T., Yoshimoto, M., Mcgrath, K., Conway, S. J., Palis, J., and Yoder, M. C. (2008). All primitive and definitive hematopoietic progenitor cells emerging before E10 in the mouse embryo are products of the yolk sac. Blood 111, 34353438. doi: 10.1182/blood-2007-08-107086

Matouk, C. C., and Marsden, P. A. (2008). Epigenetic regulation of vascular endothelial gene expression. Circ. Res. 102, 873-887. doi: 10.1161/CIRCRESAHA.107.171025

Miller, S., Walker, S. W., Arthur, J. R., Lewin, M. H., Pickard, K., Nicol, F, et al. (2002). Selenoprotein expression in endothelial cells from different human vasculature and species. Biochim. Biophys. Acta 1588, 85-93. doi: 10.1016/S0925-4439(02)00143-6

Murthi, P., Hiden, U., Rajaraman, G., Liu, H., Borg, A. J., Coombes, F., et al. (2008). Novel homeobox genes are differentially expressed in placental microvascular endothelial cells compared with macrovascular cells. Placenta 29, 624-630. doi 10.1016/j.placenta.2008.04.006

Murthi, P., So, M., Gude, N. M., Doherty, V. L., Brennecke, S. P., and Kalionis, B. (2007). Homeobox genes are differentially expressed in macrovascular human umbilical vein endothelial cells and microvascular placental endothelial cells. Placenta 28, 219-223. doi: 10.1016/j.placenta.2006.02.012

Ohtani, K., Vlachojannis, G. J., Koyanagi, M., Boeckel, J. N., Urbich, C., Farcas, R., et al. (2011). Epigenetic regulation of endothelial lineage committed genes in pro-angiogenic hematopoietic and endothelial progenitor cells. Circ. Res. 109 1219-1229. doi: 10.1161/CIRCRESAHA.111.247304

Orr, A. W., Hastings, N. E., Blackman, B. R., and Wamhoff, B. R. (2010). Complex regulation and function of the inflammatory smooth muscle cell phenotype in atherosclerosis. J. Vasc. Res. 47, 168-180. doi: 10.1159/000250095

Owens, G. K., Kumar, M. S., and Wamhoff, B. R. (2004). Molecular regulation of vascular smooth muscle cell differentiation in development and disease. Physiol. Rev. 84, 767-801. doi: 10.1152/physrev.00041.2003.

Parenti, A., Morbidelli, L., Cui, X. L., Douglas, J. G., Hood, J. D., Granger, H. J., et al. (1998). Nitric oxide is an upstream signal of vascular endothelial growth factor-induced extracellular signal-regulated kinase $1 / 2$ activation in postcapillary endothelium. J. Biol. Chem. 273, 4220-4226. doi: 10.1074/jbc.273.7.4220

Peng, Y., and Jahroudi, N. (2003). The NFY transcription factor inhibits von Willebrand factor promoter activation in non-endothelial cells through recruitment of histone deacetylases. J. Biol. Chem. 278, 8385-8394. doi: 10.1074/jbc.M213156200

Pirola, L., Balcerczyk, A., Tothill, R. W., Haviv, I., Kaspi, A., Lunke, S., et al. (2011). Genome-wide analysis distinguishes hyperglycemia regulated epigenetic signatures of primary vascular cells. Genome Res. 21, 1601-1615. doi $10.1101 /$ gr.116095.110

Pojoga, L. H., Williams, J. S., Yao, T. M., Kumar, A., Raffetto, J. D., Do Nascimento, G. R., et al. (2011). Histone demethylase LSD1 deficiency during high-salt diet is associated with enhanced vascular contraction, altered NO-cGMP relaxation pathway, and hypertension. Am. J. Physiol. Heart Circ. Physiol. 301, H1862H1871. doi: 10.1152/ajpheart.00513.2011

Rao, X., Zhong, J., Zhang, S., Zhang, Y., Yu, Q., Yang, P., et al. (2011). Loss of methyl-CpG-binding domain protein 2 enhances endothelial angiogenesis and protects mice against hind-limb ischemic injury. Circulation 123, 2964-2974. doi: 10.1161/CIRCULATIONAHA.110.966408

Rossig, L., Li, H., Fisslthaler, B., Urbich, C., Fleming, I., Forstermann, U., et al. (2002). Inhibitors of histone deacetylation downregulate the expression of endothelial nitric oxide synthase and compromise endothelial cell function in vasorelaxation and angiogenesis. Circ. Res. 91, 837-844. doi: 10.1161/01.RES.0000037983.07158.B1
Rossig, L., Urbich, C., Bruhl, T., Dernbach, E., Heeschen, C., Chavakis, E., et al. (2005). Histone deacetylase activity is essential for the expression of HoxA9 and for endothelial commitment of progenitor cells. J. Exp. Med. 201, 1825-1835. doi: 10.1084/jem.20042097

Ruchko, M. V., Gorodnya, O. M., Pastukh, V. M., Swiger, B. M., Middleton, N. S., Wilson, G. L., et al. (2009). Hypoxia-induced oxidative base modifications in the VEGF hypoxia-response element are associated with transcriptionally active nucleosomes. Free Radic. Biol. Med. 46, 352-359. doi: 10.1016/j.freeradbiomed.2008.09.038

Shahani, T., Lavend'homme, R., Luttun, A., Saint-Remy, J. M., Peerlinck, K., and Jacquemin, M. (2010). Activation of human endothelial cells from specific vascular beds induces the release of a FVIII storage pool. Blood 115, 4902-4909. doi: 10.1182/blood-2009-07-232546

Shalaby, F., Rossant, J., Yamaguchi, T. P., Gertsenstein, M., Wu, X. F., Breitman, M. L., et al. (1995). Failure of blood-island formation and vasculogenesis in Flk-1-deficient mice. Nature 376, 62-66. doi: 10.1038/376062a0

Shizukuda, Y., Tang, S., Yokota, R., and Ware, J. A. (1999). Vascular endothelial growth factor-induced endothelial cell migration and proliferation depend on a nitric oxide-mediated decrease in protein kinase Cdelta activity. Circ. Res. 85, 247-256. doi: 10.1161/01.RES.85.3.247

Simard, M., Drolet, R., Blomquist, C. H., and Tremblay, Y. (2011). Human type 2 17beta-hydroxysteroid dehydrogenase in umbilical vein and artery endothelial cells: differential inactivation of sex steroids according to the vessel type. Endocrine 40, 203-211. doi: 10.1007/s12020-011-9519-5

Stefulj, J., Panzenboeck, U., Becker, T., Hirschmugl, B., Schweinzer, C., Lang, I., et al. (2009). Human endothelial cells of the placental barrier efficiently deliver cholesterol to the fetal circulation via ABCA1 and ABCG1. Circ. Res. 104, 600-608. doi: 10.1161/CIRCRESAHA.108.185066

Svensson, K. J., Kucharzewska, P., Christianson, H. C., Skold, S., Lofstedt, T., Johansson, M. C., etal. (2011). Hypoxia triggers a proangiogenic pathway involving cancer cell microvesicles and PAR-2-mediated heparin-binding EGF signaling in endothelial cells. Proc. Natl. Acad. Sci. U.S.A. 108, 13147-13152. doi: 10.1073/pnas.1104261108

Takamura, H., Kasai, H., Arita, H., and Kito, M. (1990). Phospholipid molecular species in human umbilical artery and vein endothelial cells. J. Lipid Res. 31, 709-717.

Van Rijen, H., Van Kempen, M. J., Analbers, L. J., Rook, M. B., Van Ginneken, A. C., Gros, D., et al. (1997). Gap junctions in human umbilical cord endothelial cells contain multiple connexins. Am. J. Physiol. 272, C117-C130.

Veikkola, T., Lohela, M., Ikenberg, K., Makinen, T., Korff, T., Saaristo, A., et al. (2003). Intrinsic versus microenvironmental regulation of lymphatic endothelial cell phenotype and function. FASEB J. 17, 2006-2013. doi: 10.1096/fj.03-01 $79 \mathrm{com}$

Wang, G. G., Allis, C. D., and Chi, P. (2007a). Chromatin remodeling and cancer, Part I: covalent histone modifications. Trends Mol. Medic. 13, 363-372. doi: 10.1016/j.molmed.2007.07.003

Wang, G. G., Allis, C. D., and Chi, P. (2007b). Chromatin remodeling and cancer, Part II: ATP-dependent chromatin remodeling. Trends Mol. Med. 13, 373-380. doi: 10.1016/j.molmed.2007.07.004

Wang, K., Jiang, Y. Z., Chen, D. B., and Zheng, J. (2009). Hypoxia enhances FGF2and VEGF-stimulated human placental artery endothelial cell proliferation: roles of MEK1/2/ERK1/2 and PI3K/AKT1 pathways. Placenta 30, 1045-1051. doi: 10.1016/j.placenta.2009.10.007

Wang, W., Ha, C. H., Jhun, B. S., Wong, C., Jain, M. K., and Jin, Z. G. (2010). Fluid shear stress stimulates phosphorylation-dependent nuclear export of HDAC5 and mediates expression of KLF2 and eNOS. Blood 115, 2971-2979. doi: 10.1182/blood-2009-05-224824

Wu, J., Iwata, F., Grass, J. A., Osborne, C. S., Elnitski, L., Fraser, P., et al. (2005). Molecular determinants of NOTCH4 transcription in vascular endothelium. Mol. Cell. Biol. 25, 1458-1474. doi: 10.1128/MCB.25.4.1458-1474.2005

Xu, X. F., Ma, X. L., Shen, Z., Wu, X. L., Cheng, F., and Du, L. Z. (2010). Epigenetic regulation of the endothelial nitric oxide synthase gene in persistent pulmonary hypertension of the newborn rat. J. Hypertens. 28, 2227-2235. doi: 10.1097/HJH.0b013e32833e08f1

Zampetaki, A., Zeng, L., Margariti, A., Xiao, Q., Li, H., Zhang, Z., et al. (2010). Histone deacetylase 3 is critical in endothelial survival and atherosclerosis development in response to disturbed flow. Circulation 121, 132-142. doi: 10.1161/CIRCULATIONAHA.109.890491 
Zeng, L., Xiao, Q., Margariti, A., Zhang, Z., Zampetaki, A., Patel, S., et al. (2006). HDAC3 is crucial in shear- and VEGF-induced stem cell differentiation toward endothelial cells. J .Cell Biol. 174, 1059-1069. doi: 10.1083/jcb.200 605113

Conflict of Interest Statement: The authors declare that the research was conducted in the absence of any commercial or financial relationships that could be construed as a potential conflict of interest.

Received: 15 February 2014; paper pending published: 26 February 2014; accepted: 06 March 2014; published online: 27 March 2014.
Citation: Casanello P, Schneider D, Herrera EA, Uauy R and Krause BJ (2014) Endothelial heterogeneity in the umbilico-placental unit: DNA methylation as an innuendo of epigenetic diversity. Front. Pharmacol. 5:49. doi:10.3389/fphar.2014.00049

This article was submitted to Cardiovascular and Smooth Muscle Pharmacology, a section of the journal Frontiers in Pharmacology.

Copyright () 2014 Casanello, Schneider, Herrera, Uauy and Krause. This is an openaccess article distributed under the terms of the Creative Commons Attribution License (CC BY). The use, distribution or reproduction in other forums is permitted, provided the original author(s) or licensor are credited and that the original publication in this journal is cited, in accordance with accepted academic practice. No use, distribution or reproduction is permitted which does not comply with these terms. 